\title{
Telomere length is correlated with mitochondrial DNA copy number in intestinal, but not diffuse, gastric cancer
}

\author{
SOO-JUNG JUNG ${ }^{1 *}$, JI-HYOUNG CHO $^{2 *}$, WON-JIN PARK ${ }^{1}$, YU-RAN HEO ${ }^{1}$ and JAE-HO LEE ${ }^{1}$ \\ Departments of ${ }^{1}$ Anatomy, ${ }^{2}$ General Surgery, School of Medicine, Keimyung University, Daegu, Republic of Korea
}

Received September 27, 2016; Accepted March 3, 2017

DOI: $10.3892 / \mathrm{ol} .2017 .6197$

\begin{abstract}
A positive correlation between telomere length and mitochondrial DNA (mtDNA) copy number has previously been observed in healthy individuals, and in patients with psychiatric disorders. In the present study, telomere length and mtDNA copy number were evaluated in gastric cancer (GC) tissue samples. DNA was extracted from 109 GC samples (including 82 intestinal, and 27 diffuse cases), and the telomere length and mtDNA copy number were analyzed using a quantitative-polymerase chain reaction assay. The relative telomere length and mtDNA copy number in tumor tissue, as compared with in normal tissue, (mean \pm standard deviation) in all GC samples were $11.48 \pm 1.14$ and $14.86 \pm 1.35$, respectively. Telomere length and mtDNA copy number were not identified as exhibiting clinical or prognostic value for GC. However, positive correlations between telomere length and mitochondrial DNA copy number were identified in GC $(\mathrm{r}=0.408, \mathrm{P}<0.001)$ and in the adjacent normal mucosa $(\mathrm{r}=0.363 ; \mathrm{P}<0.001)$. When stratified by Lauren classification, the correlation was identified in intestinal type GC samples ( $\mathrm{r}=0.461 ; \mathrm{P}<0.001)$, but not in diffuse type $\mathrm{GC}$ samples $(\mathrm{r}=0.225 ; \mathrm{P}=0.260)$. This result indicated that loss of the correlation of telomeres and mitochondrial function may induce the initiation or progression of GC pathogenesis.
\end{abstract}

\section{Introduction}

Gastric cancer (GC) is highly prevalent in Asia, and is the one of the leading causes of mortality, following lung cancer and liver cancer, in Korea (1). Its development has been revealed to be a multi-step process, ranging from chronic gastritis to atrophy, intestinal metaplasia, dysplasia and, finally, invasive

Correspondence to: Dr Jae-Ho Lee, Department of Anatomy, School of Medicine, Keimyung University, 2800 Dalgubeol Boulevard, Dalseo, Daegu 42601, Republic of Korea

E-mail: anato82@dsmc.or.kr

*Contributed equally

Key words: gastric cancer, mitochondria DNA copy number, telomere, intestinal type, diffuse type cancer (2). The major histological type of GCs are adenocarcinomas, which are subdivided into intestinal type, diffuse type and mixed/unclassifiable type by Lauren classification (3). Previous studies have demonstrated that intestinal and diffuse types of GC evolve via distinct genetic pathways (3-6).

Telomeres, which contain TTAGGG repeat sequences in humans, are nucleoprotein complexes that cap each end of a eukaryotic chromosome (7). Mitochondrial DNA (mtDNA) differs from nuclear DNA, and multiple copies of mtDNA are present in each mitochondrion (8). Previous studies have demonstrated that telomere length (TL) and the mtDNA copy number $(\mathrm{mtCN})$ are associated with numerous diseases, particularly specific types of cancer (9-12). In a number of examined cancer types, TL and mtCN changes were significantly associated with clinical and prognostic characteristics, suggesting an early and important effect on carcinogenesis (10-12). Previous studies have demonstrated a sequential accumulation of mitochondrial genetic changes during the progression from chronic gastritis to cancer via intestinal metaplasia and dysplasia (11-14).

Recent studies have indicated that TL and $\mathrm{mtCN}$ are positively correlated in healthy individuals and in pregnant females (15-17). Genetic changes in the telomeres and mtDNA independently serve important roles in cellular senescence (18). mtDNA damage caused by cellular senescence may contribute to the production of reactive oxygen species (ROS), resulting in telomere shortening (18). Past reviews have emphasized the importance of the telomere-p53-mitochondrion axis for cancer, suggesting that this may be targeted in future cancer therapy $(19,20)$. Our recent studies $(21,22)$ have also investigated these genetic changes in GC; however, their association has yet to be studied in cancer tissue samples.

In the present study, TL and $\mathrm{mtCN}$ were evaluated in $\mathrm{GC}$, including 27 diffuse and 82 intestinal type tissue samples. The results of the present study may aid improvements in the current understanding of GC, through identifying the role of mtDNA and TL in GC pathogenesis.

\section{Materials and methods}

Patients and DNA extraction. Tissue samples from a total of 109 patients $(57.97 \pm 11.74$ years old; 82 male and 27 female patients), who underwent gastrectomy to treat gastric adenocarcinoma between October 1999 and December 2001, were selected from an archive of paraffin blocks at Keimyung University 
Dongsan Hospital (Daegu, Korea). Two experienced pathologists reviewed all cases, and the tumor and adjacent normal mucosa tissue areas were defined according to hematoxylin and eosin stained sections. Tissue sections were deparaffinized with $500 \mu 1100 \%$ xylene, and left in a $65^{\circ} \mathrm{C}$ water bath for $15 \mathrm{~min}$. To remove the residual xylene, the samples were washed five times with ethanol. The selected areas from the paraffin-embedded tissues then underwent DNA extraction. DNA was isolated using an Absolute ${ }^{\mathrm{TM}}$ DNA Extraction kit (BioSewoom, Inc., Seoul, Korea), according to the manufacturer's protocol. DNA quantity and quality were measured using NanoDrop 1000 (Thermo Fisher Scientific, Inc., Pittsburgh, PA, USA).

Determination of $T L$ and $m t C N$. TL and $m t C N$ were analyzed by quantitative-polymerase chain reaction (q-PCR). For the quantitative determination of $\mathrm{TL}$ and $\operatorname{mtCN}(T)$ relative to $\beta$-globin (a control from nucleic DNA, $S$ ), primers for the specific amplification of telomeric repeats and cytochrome $c$ oxidase subunit I (COX I; a gene in mtDNA) were selected (Table I). q-PCR was then performed using a LightCycler ${ }^{\circledR} 480$ II system (Roche Diagnostics GmbH, Mannheim Germany). The PCR conditions were: $95^{\circ} \mathrm{C}$ denaturation for $1 \mathrm{~min}$; 40 cycles of $95^{\circ} \mathrm{C}$ for $10 \mathrm{sec}$; and $60^{\circ} \mathrm{C}$ for $30 \mathrm{sec}$. Relative TL and $\mathrm{mtCN}$ were determined by calculating $T / S$ values using the following formula: $T / S=2^{-\Delta \mathrm{Cq}}$, where ${ }^{\Delta \mathrm{Cq}}=($ mean $\mathrm{Cq}$ telomere or COX I)-(mean Cq $\beta$-globin) $(23,24)$. Each measurement was repeated in triplicate; five serially diluted control samples were also included in each experiment.

Statistical analysis. The SPSS statistical package version 19.0 for Windows (IBM SPSS, Armonk, NY, USA) was used for all statistical analyses. TL and $\mathrm{mtCN}$ are presented as the mean \pm standard deviation (SD). Pearson correlation coefficients were calculated to evaluate the association between TL and $\mathrm{mtCN}$. To further explore the correlation between these markers and the prognosis of GC, a fold change in the TL or mtCN in tumors $(\mathrm{T})$, compared with that in paired normal tissues $(\mathrm{N})$, was calculated $(\mathrm{T} / \mathrm{N})$. Patients were categorized into two subgroups, 'longer' and 'shorter' for TL, and 'low' and 'high' for $\mathrm{mtCN}$, according to their median TL and $\mathrm{mtCN}$ T/N values. Survival curves, estimated using the Kaplan-Meier method (univariate analysis), were compared with a log-rank test. Overall survival (OS) time was defined as the time from diagnosis to mortality from cancer or other causes. A two-tailed $\mathrm{P}<0.05$ was considered to indicate a statistically significant difference.

\section{Results}

TL and mtCN do not significantly differ between intestinal and diffuse GC. TL and mtCN were analyzed in samples obtained from 109 patients with GC $(60.0 \pm 11.8$ years of age $)$ using q-PCR. TL and $\mathrm{mtCN}$ T/N values were $11.48 \pm 1.14$ and $14.86 \pm 1.35$, respectively (fold change; mean \pm SD; Table I). When stratified by Lauren classification, the mtCN was similar in intestinal $(14.39 \pm 1.61)$ and diffuse $(16.34 \pm 2.44)$ types of GC $(\mathrm{P}=0.540)$. TL was shorter in intestinal type samples $(10.36 \pm 1.27)$, as compared with in diffuse type samples $(15.02 \pm 2.45)$; however, this was not to a statistically significant extent $(\mathrm{P}=0.074)$.
Table I. Primers used in this study.

\begin{tabular}{ll}
\hline Primer & \multicolumn{1}{c}{ Sequence } \\
\hline $\begin{array}{c}\text { Telomere } \\
\text { Forward }\end{array}$ & 5'-CGGTTTGTTTGGGTTTGGGTTTGGGT \\
& TTGGGTTTGGGTT-3' \\
Reverse & 5'-GGCTTGCCTTACCCTTACCCTTACC \\
& C-TTACCCTTACCCT-3' \\
COX I & \\
Forward & 5'-TTCGCCGACCGTTGACTATTCTCT-3' \\
Reverse & 5'-AAGATTATTACAAATGCATGGGC-3' \\
3-globin & \\
Forward & 5'-TGTGCTGGCCCATCACTTTG-3' \\
Reverse & 5'-ACCAGCCA-CCACTTTCTGATAGG-3' \\
\hline
\end{tabular}

Table II. Telomere length and mitochondrial DNA copy number in gastric cancer.

\begin{tabular}{lcccc}
\hline & & \multicolumn{2}{c}{ Lauren classification } & \\
\cline { 3 - 4 } Variables & Total & Intestinal & Diffuse & P-value \\
\hline $\begin{array}{l}\mathrm{TL} \\
(\text { mean } \pm \text { SD) }\end{array}$ & $11.48 \pm 1.14$ & $10.36 \pm 1.27$ & $15.02 \pm 2.45$ & 0.074 \\
$\begin{array}{l}\text { MtCN } \\
(\text { mean } \pm \text { SD) }\end{array}$ & $14.86 \pm 1.35$ & $14.39 \pm 1.61$ & $16.34 \pm 2.44$ & 0.540 \\
\hline
\end{tabular}

$\mathrm{SD}$, standard deviation; MtCN, mitochondrial DNA copy number; TL, telomere length.

TL and mtCN are not associated with clinicopathological characteristics in patients with GC. For the consideration of the association between clinicopathological characteristics and the TL and mtCN in GC, two groups, 'longer' and 'shorter' for TL, and 'low' and 'high' for mtCN, were assigned based on the median TL and $\mathrm{mtCN}$ T/N fold change of the tissue samples. The clinicopathological characteristics of each group are presented in Table II. A shorter TL was more frequent in intestinal GC (64.6\%) compared with in diffuse GC (46.2\%), although there was no statistically significant difference $(\mathrm{P}=0.093)$. TL was identified to be shorter in females $(70.4 \%)$ than in males (57.3\%); this was also not statistically significant $(\mathrm{P}=0.229)$. Additionally, age and other clinicopathological parameters were not determined to have any significant associations with TL and $\mathrm{mtCN}$.

TL and mtCN are correlated in intestinal, but not diffuse, GC. A significant positive correlation in the $\mathrm{T} / \mathrm{N}$ fold change of $\mathrm{TL}$ and $\mathrm{mtCN}$ was identified in $\mathrm{GC}(\mathrm{r}=0.408 ; \mathrm{P}<0.001$; Fig. 1A). This correlation was also apparent in the adjacent normal mucosa $(\mathrm{r}=0.363 ; \mathrm{P}<0.001)$ obtained from the patients with GC. When stratified by Lauren classification, a significant correlation was not identified in diffuse $\mathrm{GC}(\mathrm{r}=0.225 ; \mathrm{P}=0.260$; Fig. 1B); however, there was a correlation in the intestinal type samples $(r=0.461 ; \mathrm{P}<0.001 ;$ Fig. $1 \mathrm{C})$. The stratification did 
Table III. Clinicopathological characteristics of TL and $\mathrm{mtCN}$ in gastric cancer.

\begin{tabular}{|c|c|c|c|c|}
\hline \multirow[b]{2}{*}{ Group } & \multicolumn{2}{|c|}{$\mathrm{TL}(\%, \mathrm{n})$} & \multicolumn{2}{|c|}{$\mathrm{mtCN}(\%, \mathrm{n})$} \\
\hline & Longer & Shorter & Low & High \\
\hline All patients & $39.5(43)$ & $60.5(66)$ & $69.7(76)$ & $30.3(33)$ \\
\hline \multicolumn{5}{|l|}{ Age } \\
\hline$<60$ & $37.0(20)$ & $63.0(34)$ & 72.2 (39) & $27.8(15)$ \\
\hline$\geq 60$ & $41.8(23)$ & $58.2(32)$ & $67.3(37)$ & 32.7 (18) \\
\hline \multicolumn{5}{|l|}{ Gender } \\
\hline Male & $42.7(35)$ & $57.3(47)$ & $68.3(56)$ & 31.7 (26) \\
\hline Female & $29.6(8)$ & 70.4 (19) & $74.1(20)$ & $25.9(7)$ \\
\hline \multicolumn{5}{|l|}{ pT stage } \\
\hline $1 / 2$ & $42.3(30)$ & $57.7(41)$ & $68.1(49)$ & 31.9 (23) \\
\hline $3 / 4$ & $34.2(13)$ & $65.8(25)$ & $73.0(27)$ & $27.0(10)$ \\
\hline \multicolumn{5}{|l|}{ pN stage } \\
\hline $0 / 1$ & $40.3(27)$ & $59.7(40)$ & $68.2(60)$ & $31.8(28)$ \\
\hline $2 / 3$ & $38.1(16)$ & $61.9(26)$ & $76.2(16)$ & $83.8(5)$ \\
\hline \multicolumn{5}{|l|}{$\begin{array}{l}\text { Lauren } \\
\text { classification }\end{array}$} \\
\hline Diffuse & $53.8(14)$ & $46.2(12)$ & $65.4(17)$ & $34.6(9)$ \\
\hline Intestinal & 35.4 (29) & $64.6(53)$ & 70.7 (58) & $29.3(24)$ \\
\hline \multicolumn{5}{|l|}{$\begin{array}{l}\text { Depth of } \\
\text { invasion }\end{array}$} \\
\hline Early & $39.1(18)$ & $60.9(28)$ & 71.7 (33) & $28.3(13)$ \\
\hline Advanced & $39.7(25)$ & $60.3(38)$ & $68.3(43)$ & $31.7(20)$ \\
\hline
\end{tabular}

mtCN, mitochondrial DNA copy number; TL, telomere length; pT, primary tumor; $\mathrm{pN}$, regional lymph nodes.

not reveal any significant associations with other parameters (Table III).

$T L$ and $m t C N$ are not associated with the rate of OS. The OS time and rate for patients with GC were assessed in order to identify if there was a prognostic value for TL and $\mathrm{mtCN}$. The median follow-up duration was 82.2 months (range, 3.7-158.8 months), and the 5-year OS rate was $79.3 \%$. The results indicated no prognostic value of the $\mathrm{mtCN}(\mathrm{P}=0.850)$ and TL $(\mathrm{P}=0.784)$ in $\mathrm{GC}$, based on comparing those patients with 'high' and 'low' mtCN and TL values (Fig. 2).

\section{Discussion}

The present study identified that TL is positively correlated with $\mathrm{mtCN}$ in GC tissues and paired normal tissues; this was consistent with the results of previous studies conducted on healthy volunteers (15-17). A correlation between TL and $\mathrm{mtCN}$ was initially identified in a study of 129 healthy elderly females (15); in a further study, it was also demonstrated in healthy adults and pregnant females $(16,17)$. Furthermore, certain neuropsychiatric conditions were also associated with $\mathrm{TL}$ shortening and $\mathrm{mtCN}$ increase, although detailed data concerning their association were not presented (25). Taken
A

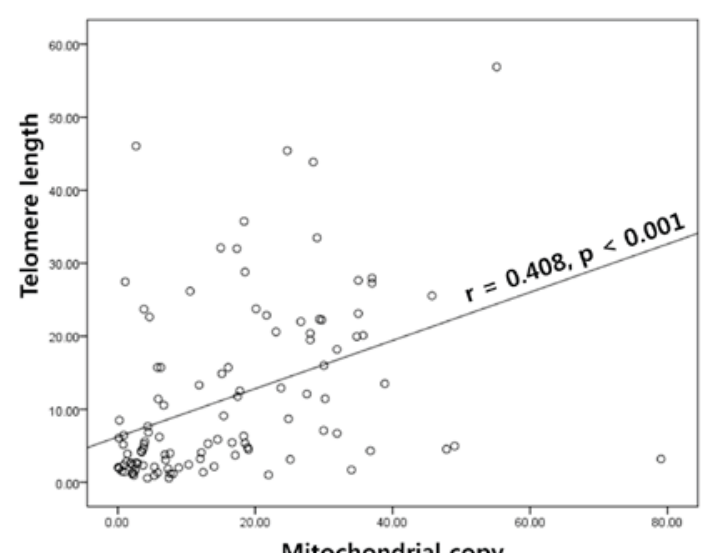

B

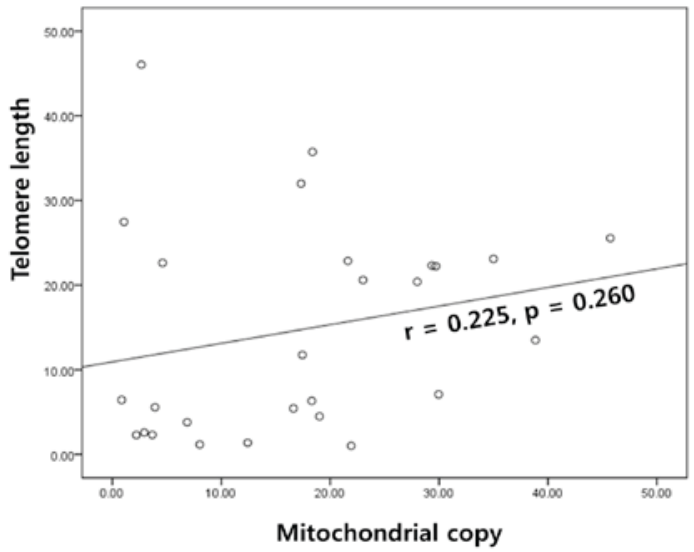

C

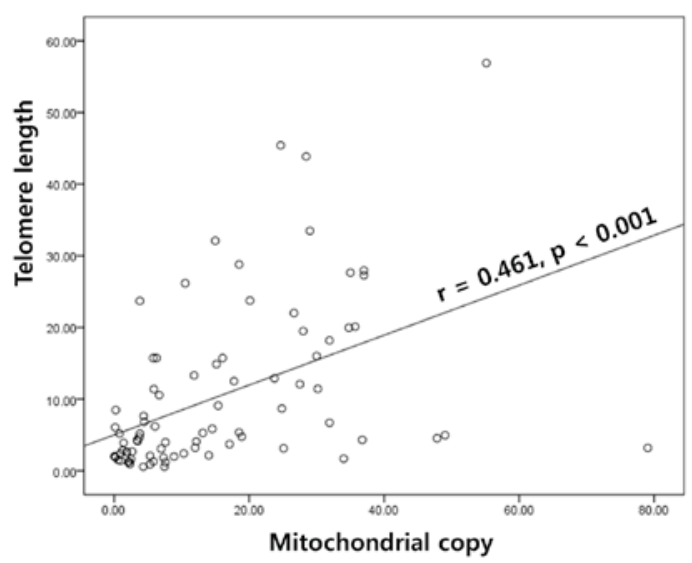

Figure 1. Association between mitochondrial DNA copy number and telomere length. (A) Telomere length and mitochondrial DNA copy number were positively correlated in gastric cancer. When stratified by Lauren classification, positive correlation was (B) not identified in the diffuse type samples; however, (C) it was identified in the intestinal type samples.

together, there is a positive correlation between TL alteration and $\mathrm{mtCN}$ not only in healthy individuals, but also in cancer tissues.

The clinicopathological significance of TL and mitochondrial genetic change has been previously studied in GC by a number of groups $(11,12,14,21,22)$. TL was previously demonstrated to differ in GC according to Helicobacter pylori infection status, microsatellite instability (MSI), and non-steroidal anti-inflammatory drug use (26-29). Although TL change was identified in gastric carcinogenesis, it was not associated with clinicopathological features or prognosis 
A

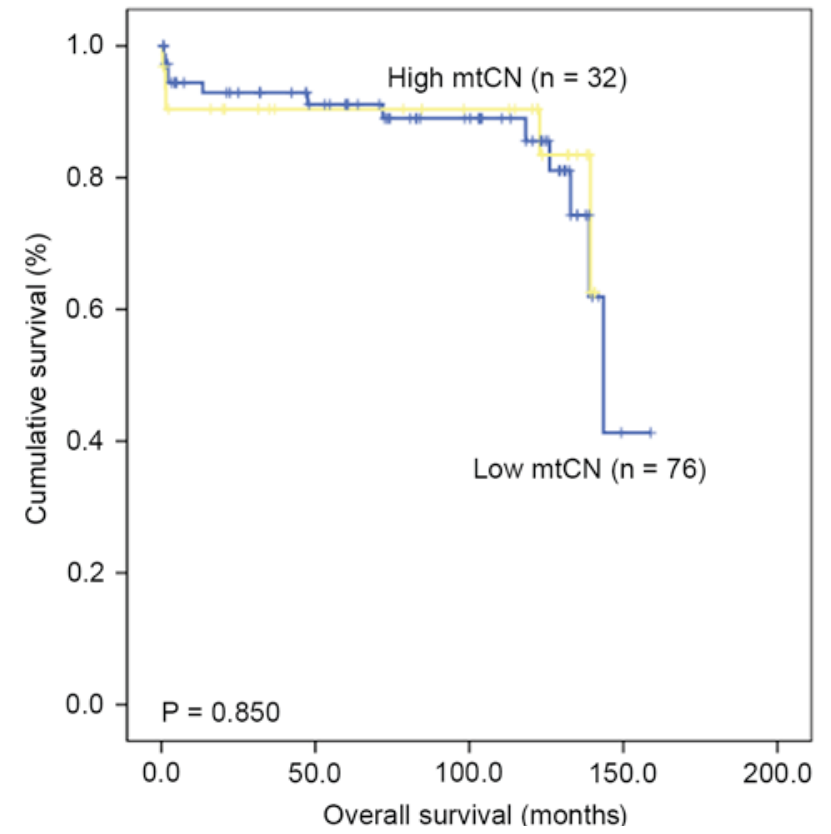

B

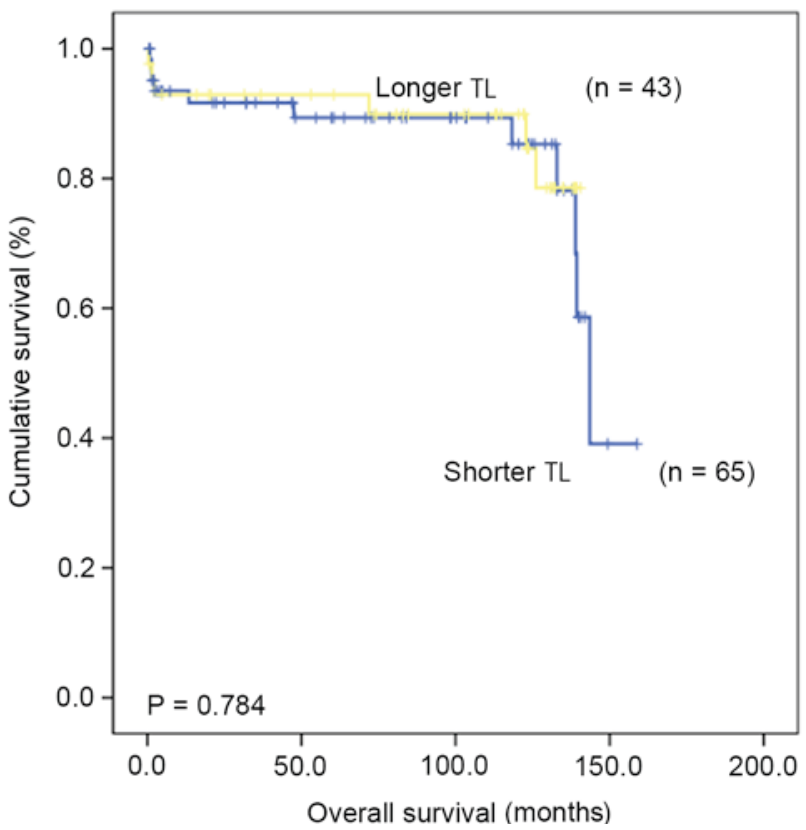

Figure 2. Kaplan-Meier plots depicting an overall survival rate analysis of gastric cancer according to (A) mtCN and (B) TL. No significant difference was identified. mtCN, mitochondrial DNA copy number; TL, telomere length.

in the present study. However, Pascua et al (27) reported that a combination of TL with MSI status has prognostic value. Mitochondrial genetic change has been frequently studied in GC, and our previous study (30) identified mtMSI to be a novel genetic marker for GC susceptibility. It was demonstrated that mtMSI was present in $10.2 \%$ of GC samples and $12.5 \%$ of gastric dysplasia samples, and that mtMSI was associated with a poor prognosis and an increased potential for progression.

In the present study, TL was marginally shorter in intestinal type GC, as compared with in diffuse type GC, whereas $\mathrm{TL}$ and $\mathrm{mtCN}$ did not have any significant association with clinical characteristics. However, a notable association was identified in GC tissues; in accordance with previous studies on healthy individuals $(15-17,25), \mathrm{mtCN}$ and $\mathrm{TL}$ were identified to be correlated with each other in normal and cancerous tissues obtained from patients with GC. A positive association was also identified in intestinal type GC, but not in the diffuse type. These results suggest that the normal positive correlation between telomeres and mitochondrial function is disrupted during the carcinogenesis of diffuse type GC, inducing TL change. Therefore, loss of the co-regulation of telomere length and mitochondrial copy number may serve a pivotal initiating role in gastric carcinogenesis. However, the survival analysis from the present study did not observe that this affected the clinical characteristics and further progression of GC.

Mitochondria and telomeres are considered to be key instigators of natural ageing (18). Mitochondrial dysfunction or genetic change during aging may be associated with the aging process through increased ROS production and decreased adenosine triphosphate generation (18). A previous study demonstrated that mitochondrial biogenesis and energy production were decreased in telomerase-deficient mice with severe telomere dysfunction (17). It has been hypothesized that telomere change influences not only oxidative defense mechanisms but also mitochondrial functions, including biogenesis and metabolism, in transcriptomic, molecular, genetic and functional analyses of various cells and organs, including proliferative and post-mitotic tissues $(16,17)$. Therefore, this telomere-mitochondria axis may explain how shortened telomeres can cause mitochondrial change. The results of the present study support this hypothesis, suggesting that deregulation of the telomere-mitochondria axis, as caused by aging or other physiological factors, triggers the carcinogenesis of diffuse type GC.

In summary, TL and $\mathrm{mtCN}$ are correlated in normal and cancerous stomach tissues. Additionally, abnormal regulation of the telomere-mitochondria axis was identified in diffuse type GC, although the mechanism underlying this process remains unclear. Therefore, a change in the regulation of mitochondria and telomeres may be essential for diffuse GC carcinogenesis, suggesting that this signaling pathway could be targeted for cancer prevention. Furthermore, this result improves current understanding of how telomere change may contribute not only to age-associated disorders, but also to tumorigenesis.

\section{Acknowledgements}

The present study was supported by grants from the Basic Science Research Program through the National Research Foundation of Korea funded by the Ministry of Education (NRF-2014R1A6A3A04058057) and by the Korean Government (grant no. 2014R1A5A2010008).

\section{References}

1. Jung KW, Won YJ, Oh CM, Kong HJ, Cho H, Lee JK, Lee DH and Lee KH: Prediction of cancer incidence and mortality in Korea, 2016. Cancer Res Treat 48: 451-457, 2016. 
2. Correa P and Shiao YH: Phenotypic and genotypic events in gastric carcinogenesis. Cancer Res 54 (7 Suppl): 1941s-1943s, 1994.

3. Grabsch HI and Tan P: Gastric cancer pathology and underlying molecular mechanisms. Dig Surg 30: 150-158, 2013.

4. Yakirevich E and Resnick MB: Pathology of gastric cancer and its precursor lesions. Gastroenterol Clin North Am 42: 261-284, 2013.

5. Akhavan-Niaki $\mathrm{H}$ and Samadani AA: Molecular insight in gastric cancer induction: An overview of cancer stemness genes. Cell Biochem Biophy 68: 463-473, 2014.

6. Carcas LP: Gastric cancer review. J Carcinog 13: 14, 2014.

7. Harley CB, Futcher AB and Greider CW: Telomeres shorten during ageing of human fibroblasts. Nature 345: 458-460, 1990.

8. Anderson S, Bankier AT, Barrell BG, de Bruijn MH, Coulson AR, Drouin J, Eperon IC, Nierlich DP, Roe BA, Sanger F, et al: Sequence and organization of the human mitochondrial genome. Nature 290: 457-465, 1981.

9. Blackburn EH, Greider CW and Szostak JW: Telomeres and telomerase: The path from maize, Tetrahymena and yeast to human cancer and aging. Nat Med 12: 1133-1138, 2006.

10. Blasco MA: Telomeres and human disease: Ageing, cancer and beyond. Nat Rev Genet 6: 611-622, 2005.

11. Cui H, Huang P, Wang Z, Zhang Y, Zhang Z, Xu W, Wang X, Han Y and Guo X: Association of decreased mitochondrial DNA content with the progression of colorectal cancer. BMC Cancer 13: 110, 2013.

12. Lee HC, Li SH, Lin JC, Wu CC, Yeh DC and Wei YH: Somatic mutations in the D-loop and decrease in the copy number of mitochondrial DNA in human hepatocellular carcinoma. Mut Res 547: 71-78, 2004

13. Liao LM, Baccarelli A, Shu XO, Gao YT, Ji BT, Yang G, Li HL, Hoxha M, Dioni L, Rothman N, et al: Mitochondrial DNA copy number and risk of gastric cancer: A report from the Shanghai Women's Health Study. Cancer Epidemiol Biomarkers Prev 20: 1944-1949, 2011

14. Wu X, Amos CI, Zhu Y, Zhao H, Grossman BH, Shay JW, Luo S, Hong WK and Spitz MR: Telomere dysfunction: A potential cancer predisposition factor. J Natl Cancer Inst 95: 1211-1218, 2003.

15. Kim JH, Kim HK, Ko JH, Bang H and Lee DC: The relationship between leukocyte mitochondrial DNA copy number and telomere length in community-dwelling elderly women. PloS one 8: e67227, 2013

16. Qiu C, Enquobahrie DA, Gelaye B, Hevner K and Williams MA The association between leukocyte telomere length and mitochondrial DNA copy number in pregnant women: A pilot study. Clin Lab 61: 363-369, 2015.

17. Tyrka AR, Carpenter LL, Kao HT, Porton B, Philip NS Ridout SJ, Ridout KK and Price LH: Association of telomere length and mitochondrial DNA copy number in a community sample of healthy adults. Exp Gerontol 66: 17-20, 2015.
18. Passos JF, Saretzki G and von Zglinicki T: DNA damage in telomeres and mitochondria during cellular senescence: Is there a connection? Nucleic Acids Res 35: 7505-7513, 2007.

19. Hu J, Hwang SS, Liesa M, Gan B, Sahin E, Jaskelioff M, Ding Z, Ying H, Boutin AT, Zhang H, et al: Antitelomerase therapy provokes ALT and mitochondrial adaptive mechanisms in cancer. Cell 148: 651-663, 2012.

20. Sahin E, Colla S, Liesa M, Moslehi J, Müller FL, Guo M, Cooper M, Kotton D, Fabian AJ, Walkey C, et al: Telomere dysfunction induces metabolic and mitochondrial compromise. Nature 470: 359-365, 2011.

21. Lee H, Lee JH, Kim DC, Hwang I, Kang YN, Gwon GJ, Choi IJ and Kim S: Is mitochondrial DNA copy number associated with clinical characteristics and prognosis in gastric cancer? Asian Pac J Cancer Prev 16: 87-90, 2015.

22. Lee H, Jin JD, La BM, Park WJ, Choi IJ and Lee JH: TERT promoter mutation, telomere length and TERT expression in gastric cancer. Int J Clin Exp Pathol 9: 1758-1763, 2016.

23. Gil ME and Coetzer TL: Real-time quantitative PCR of telomere length. Mol Biotechnol 27: 169-172, 2004

24. Lee JH, Hwang I, Kang YN, Choi IJ and Kim DK: Genetic characteristics of mitochondrial DNA was associated with colorectal carcinogenesis and its prognosis. PloS One 10: e0118612, 2015.

25. Tyrka AR, Parade SH, Price LH, Kao HT, Porton B, Philip NS, Welch ES and Carpenter LL: Alterations of mitochondrial DNA copy number and telomere length with early adversity and psychopathology. Biol Psychiatry 79: 78-86, 2016.

26. Aslan R, Bektas A, Bedir A, Alacam H, Aslan MS, Nar R, Yildirim B, Goren I, Ecemis O, Ustaoglu M, et al: Helicobacter pylori eradication increases telomere length in gastric mucosa. Hepatogastroenterology 60: 601-604, 2013.

27. Pascua I, Fernández-Marcelo T, Sánchez-Pernaute A, de Juan C, Head J, Torres-García AJ and Iniesta P: Prognostic value of telomere function in gastric cancers with and without microsatellite instability. Eur J Gastroenterol Hepatol 27: 162-169, 2015.

28. Tahara T, Shibata T, Kawamura T, Ishizuka T, Okubo M, Nagasaka M, Nakagawa Y, Arisawa T, Ohmiya N and Hirata I: Telomere length in non-neoplastic gastric mucosa and its relationship to H. pylori infection, degree of gastritis and NSAID use. Clin Exp Med 16: 65-71, 2016.

29. Tahara T, Shibata T, Okubo M, Kawamura T, Horiguchi N, Ishizuka T, Nakani N, Nagasaka M, Nakagawa Y and Ohmiya N: Demonstration of potential link between helicobacter pylori related promoter $\mathrm{CpG}$ island methylation and telomere shortening in human gastric mucosa. Oncotarget 7: 43989-43996, 2016.

30. Jeong CW, Lee JH, Sohn SS, Ryu SW and Kim DK: Mitochondrial microsatellite instability in gastric cancer and gastric epithelial dysplasia as a precancerous lesion. Cancer Epidemiol 34: 323-327, 2010. 